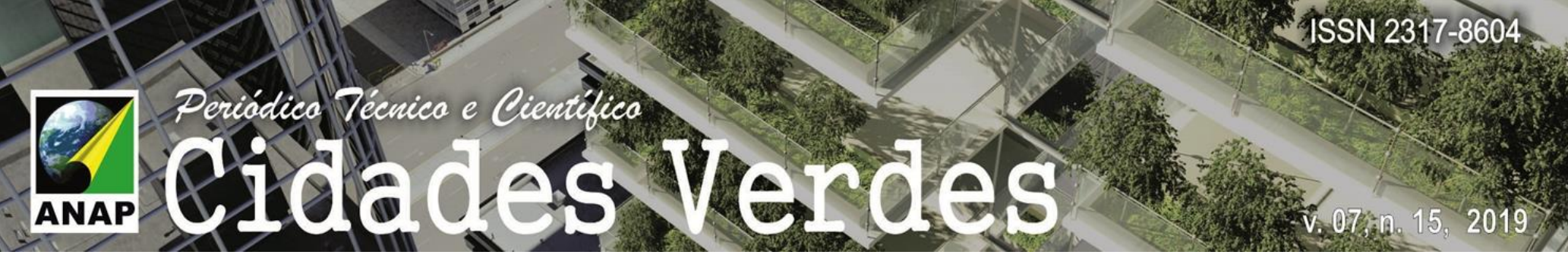

\title{
Composição florística e sua espacialização em praça centenária de Itaqui-RS
}

Floristic composition and your spacialization in centenary square in the city of Itaqui-RS

Composición florística y su espacialización en plaza centenaria en la ciudad de Itaqui-RS

Luciana Zago Ethur

Professora Doutora do Campus Itaqui, UNIPAMPA, Brasil

lucianaethur@unipampa.edu.br

Mariza Moraes Ponce

Graduanda em Agronomia, UNIPAMPA, Brasil

poncemah@gmail.com

Sidnei Luís Bohn Gass

Professor Doutor do Campus Itaqui, UNIPAMPA, Brasil

sidneigass@unipampa.edu.br

Dieison Morozoli da Silva

Bel. Ciência e Tecnologia e Graduando em Engenharia de Cartografia e Agrimensura, UNIPAMPA, Brasil.

dieison.ufp@gmail.com 


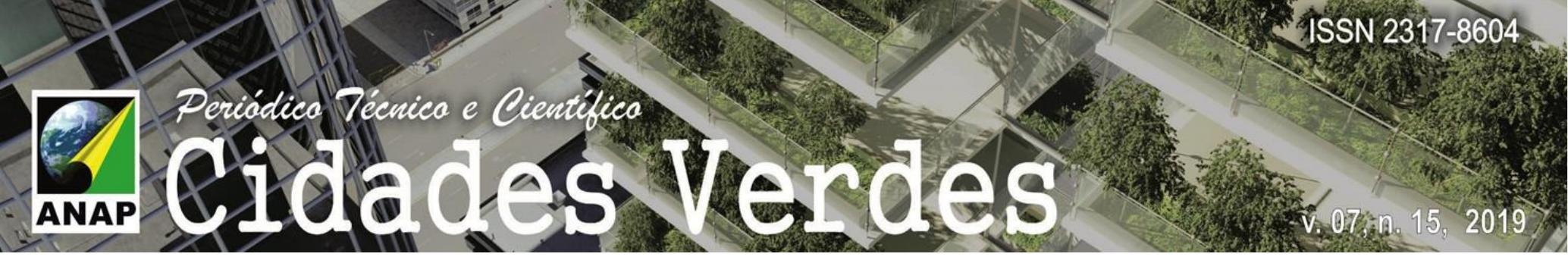

\section{RESUMO}

O conhecimento sobre a composição florística de praças e parques auxilia no estudo desses espaços para o planejamento e gestão de áreas verdes urbanas. $O$ objetivo desse trabalho foi realizar o levantamento da composição florística e sua espacialização na Praça Marechal Deodoro da Fonseca, em Itaqui - RS. Para a caracterização da composição florística foi realizado o preenchimento de um formulário, com as informações: nome popular, nome científico, porte (árvore, arbusto, pinheiro, palmeira e cactos), status (nativa ou exótica), condições do fuste, condições da copa e conflitos com fiação aérea ou calçadas. A praça apresenta 368 plantas, sendo 237 árvores, 88 arbustos, 12 pinheiros, 30 palmeiras e 1 cactos. Foram identificadas 28 famílias botânicas, sendo que a Fabaceae foi a mais expressiva e as plantas exóticas se sobressaíram às nativas. A composição florística da Praça Marechal Deodoro da Fonseca, de Itaqui - RS, cumpre com sua função ambiental quanto à área verde urbana, além de ser um local utilizado pela população para o lazer e convivência. Entretanto, observou-se falta de planejamento com relação à escolha das plantas e o espaço utilizado para o plantio. Parte das árvores encontradas na praça, principalmente no seu entorno, são velhas, com avarias na copa e ou no fuste, e nesse sentido, existe a necessidade de ser realizado um estudo para a renovação e manutenção desse espaço.

PALAVRAS-CHAVE: Biodiversidade. Áreas verdes. Planejamento urbano.

\section{ABSTRACT}

Knowledge about the floristic composition of squares and parks helps to study these spaces for the planning and management of the urban green areas. The objective of this work was to carry out the survey of the floristic composition and its spacialization in Marechal Deodoro da Fonseca square, in the city of Itaqui - RS. For the characterization of the floristic composition, a form was filled out, with the informations: popular name, scientific name, size (tree, shrub, pine, palm and cactus), status (native or exotic), stem conditions, canopy and conflicts with aerial spinning or conflicts with sidewalks. The square presents 368 plants, being 237 trees, 88 shrubs, 12 pines, 30 palm and 1 cactus. Twenty-eight botanical families were identified, with Fabaceae being the most expressive. Exotic plants occurred in greater quantity than the native ones. The floristic composition of square, in the city of Itaqui, fulfills its environmental function regarding the urban green area, besides being a place used by the population for leisure and coexistence. However, there was a lack of planning regarding with the choice of plants and with the space used for planting. Some of the trees found in the square, mainly in their surroundings, are old, with problems in the canopy and or in the stem. In this sense, there is a need to carry out a study for the renovation and maintenance of this space.

KEYWORDS: Biodiversity. Green areas. Urban planning.

\section{RESUMEN}

El conocimiento sobre la composición florística de plazas y parques ayuda en el estudio de esos espacios para la planificación y gestión de esas áreas verdes urbanas. El objetivo de este trabajo fue realizar el levantamiento de la composición florística y su espacialización en la Plaza Marechal Deodoro da Fonseca, en Itaqui - RS. Para la caracterización de la composición florística se realizó el llenado de un formulario, con las informaciones: nombre popular, nombre científico, porte (árbol, arbusto, pino, palmera y cactus), origen (nativo o exótico), condiciones del fuste, condiciones de las copas y conflictos con hilandería aérea o calzadas. La plaza presenta 368 plantas, siendo 237 árboles, 88 arbustos, 12 pinos, 30 palmeras y 1 cactus. Se identificaron 28 familias botánicas, siendo que la Fabaceae fue la más expresiva y las plantas exóticas se sobresalieron a las nativas. La composición florística de la Plaza Marechal Deodoro da Fonseca, de Itaqui - RS, cumple con su función ambiental en cuanto al área verde urbana, además de ser un lugar utilizado por la población para el ocio y convivencia. Sin embargo, se observó falta de planificación con relación a la elección de las plantas y el espacio utilizado para la siembra. Una parte de los árboles encontrados en la plaza, principalmente en su entorno son viejos, con problemas en la copa y en el fuste, y en ese sentido, existe la necesidad de ser realizado un estudio para la renovación y mantenimiento de ese espacio.

PALABRAS CLAVE: Biodiversidad. Areas verdes. planeamiento público. 


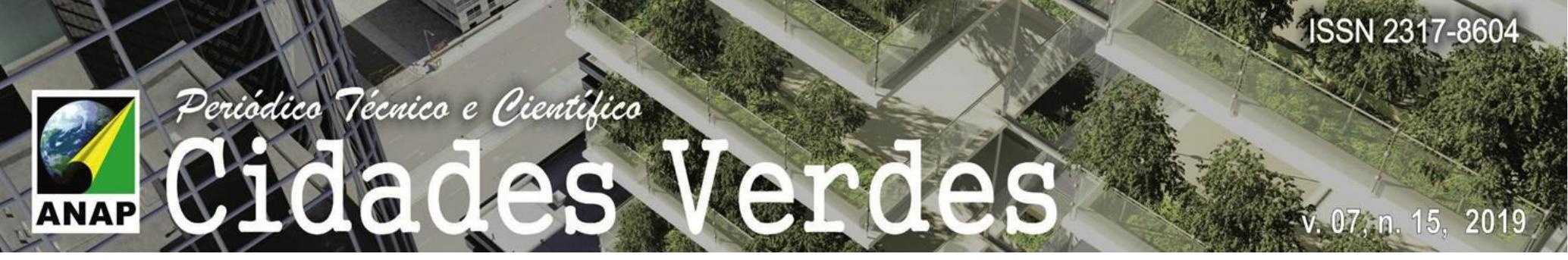

\section{INTRODUÇÃO}

A vegetação é de extrema importância para as cidades, pois está relacionada com o paisagismo, com a melhoria do ar, diminuição do aquecimento devido às áreas de concreto, melhor fluidez da água quando das chuvas e por trazer e manter a fauna nas cidades. Conforme Garcia e Parfitt (2015), nos dias de hoje, mais de $80 \%$ da população brasileira vive e trabalha em áreas urbanas; cidades de pequeno, médio e grande porte que são responsáveis por receber e abrigar todos esses habitantes. Contudo, não são nesses locais que necessariamente se encontram as melhores condições de vida principalmente no que se refere ao meio ambiente.

O município de Itaqui-RS completa 159 anos de emancipação no ano de 2017 e apresenta além de prédios centenários, como o Teatro Prezewodowski, uma praça central - Marechal Deodoro da Fonseca, que foi se transformando com o passar dos anos. Observa-se na área urbana, três principais locais de arborização; o mais recente, o Parque Comendador Firmino; uma área de mata ripária, do rio Uruguai; e o terceiro, de árvores centenárias, a Praça Marechal Deodoro da Fonseca. Não existem registros sobre quando a praça foi arborizada e nem sobre sua composição florística, sendo que árvores já foram perdidas devido a fenômenos naturais. Nesse sentido, existe preocupação em registrar a composição florística da praça, inclusive porque o conhecimento acerca da biodiversidade da flora local poderá ser usado para organização de posteriores trabalhos em educação ambiental, partindo-se do princípio que o conhecimento traz a sensibilização e o respeito. Precisa-se, cada vez mais, ter-se cuidado com as áreas verdes das cidades, sejam essas de pequeno ou grande porte. Segundo Carvalho et al. (2007) as áreas verdes urbanas são fundamentais para a manutenção do microclima, redução da poluição sonora, melhoria da qualidade de vida da população e como refúgio aos animais.

A composição florística dos espaços urbanos é melhor compreendida quando acompanhada de sua espacialização (Dourado e Silva, 2005; Oliveira e Jesus, 2011; Brito et al., 2012; Garcia \& Parfitt, 2015), orientando sobre a posição e a ocupação de determinadas plantas, no contexto das áreas foco de análise e estudo.

De acordo com o exposto sobre a importância das áreas verdes urbanas, a presente pesquisa teve por objetivo realizar o levantamento da composição florística e sua espacialização na Praça Marechal Deodoro da Fonseca, em Itaqui - RS.

\section{METODOLOGIA}

\subsection{LOCALIZAÇÃO E CARACTERÍSTICAS DE ITAQUI}

O município de Itaqui localiza-se na fronteira oeste do estado do Rio Grande do Sul (Figura 1), às margens do rio Uruguai e conta com uma área de $3.406 \mathrm{~km}^{2}$. De acordo com os dados do Instituto Brasileiro de Geografia e Estatística (IBGE, 2017), sua população estimada (2016) é de 39.049 habitantes, sendo sua economia baseada no cultivo de arroz e na produção pecuária. 


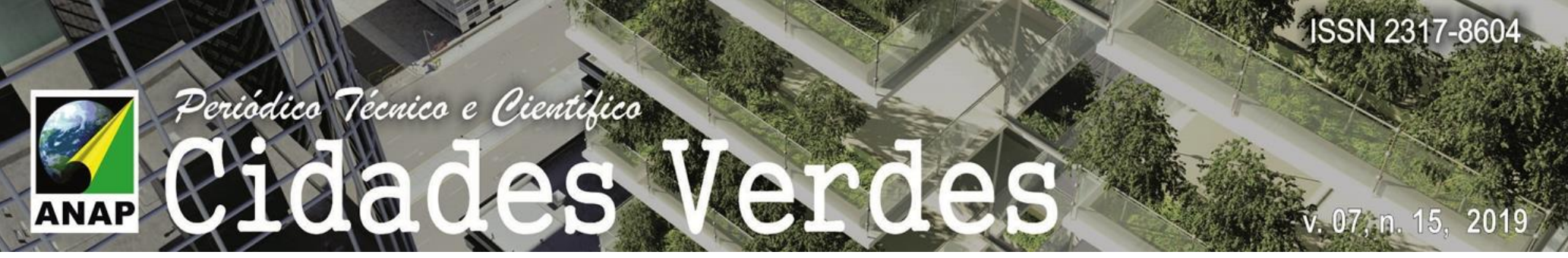

Figura 2: Mapa informando os quadrantes (total de 22), o contorno da praça e os canteiros menores, utilizados para orientar a coleta de informações e identificação das plantas.

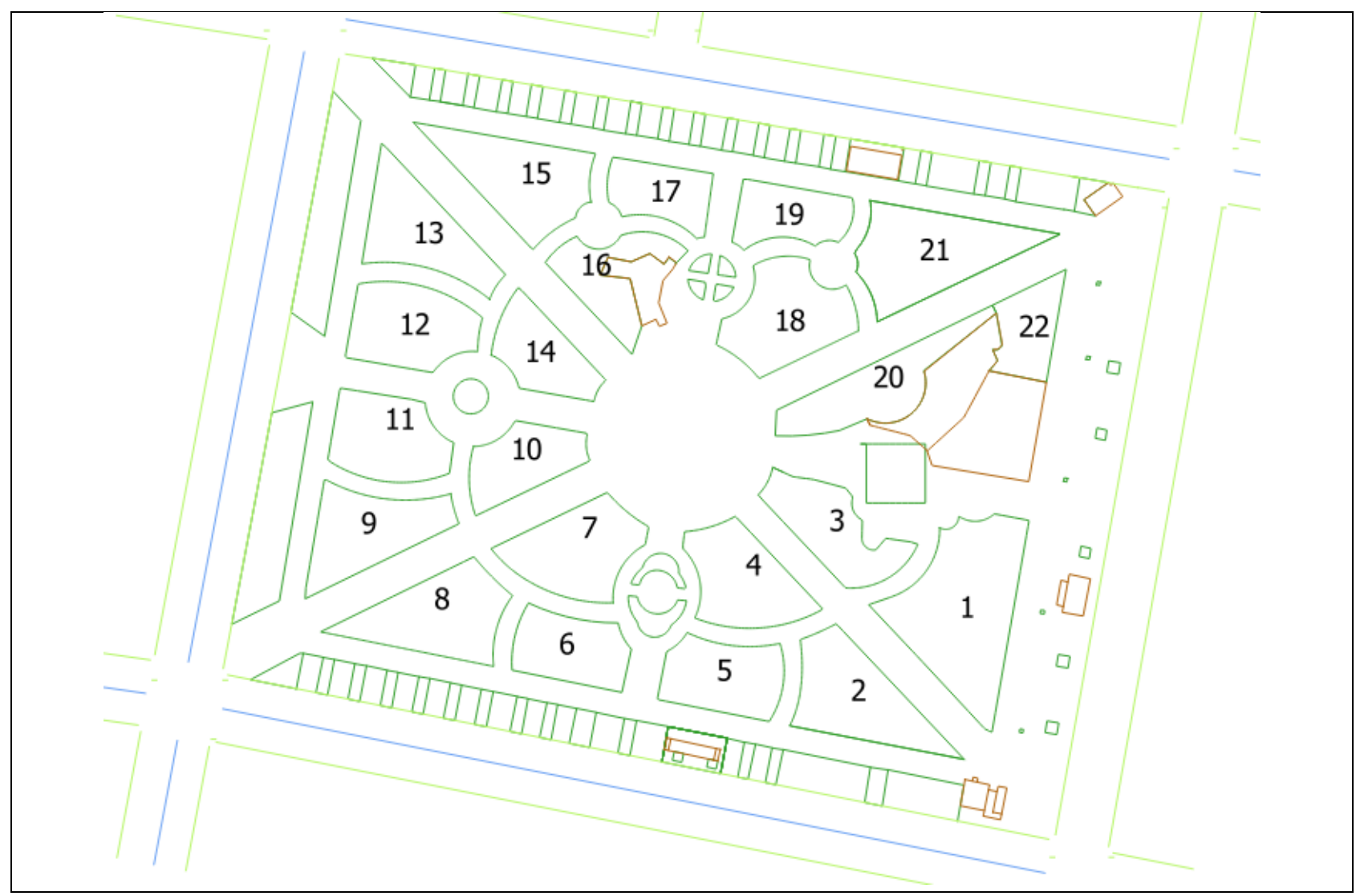

(Fonte: elaborado pelos autores)

\subsubsection{IDENTIFICAÇÃO DAS ESPÉCIES}

As plantas, em cada quadrante, foram numeradas e fotografadas. Quando foi possível, foram coletados ramos floridos para a organização de exsicatas, porém devido à altura considerável de muitas delas, foram coletados frutos e sementes presentes no solo.

Foram realizadas coletas e registros fotográficos mensais, no período de dezembro de 2015 a fevereiro de 2017. O material vegetal coletado foi guarnecido em sacos plásticos, identificados de acordo com o quadrante da coleta, e levados para o Laboratório de Biologia, do Campus Itaqui/Universidade Federal do Pampa (UNIPAMPA), para a identificação das espécies ou gêneros botânicos. A identificação das espécies foi efetuada com auxílio de bibliografia especializada e chaves analíticas dicotômicas (LORENZI, 2002a; LORENZI, 2002b; BACKES \& NARDINO, 2003; LORENZI et al., 2003; BACKES \& NARDINO, 2004; LUSA \& BONA, 2009; SOUZA \& LORENZI, 2012). A classificação foi de acordo com a utilizada por SOUZA \& LORENZI (2012) baseada na APG III (Angiosperm Phylogeny Group). 


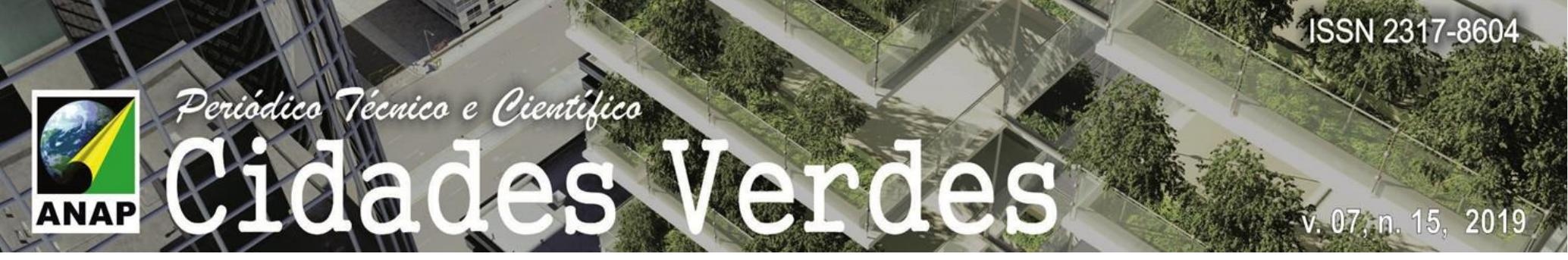

\subsubsection{ORGANIZAÇÃO DOS DADOS}

Para a caracterização da composição florística foi realizado o preenchimento de um formulário, por quadrante, com as seguintes informações: número (de acordo com a posição no quadrante), nome popular, nome científico, porte (árvore, arbusto, pinheiro, palmeira e cactos), status (nativa ou exótica), condições do fuste, condições da copa e conflitos com fiação aérea ou calçadas.

Avaliação das condições do fuste e da copa, adaptado de Maranho \& Paula, (2014). Qualidade da copa classificada como normal - a que se apresentou inteira e bem distribuída; levemente deformada - com poucos galhos quebrados; deformada - com $1 / 3$ dos galhos quebrados ou secos; muito deformada - com mais da metade dos galhos quebrados ou secos; e dano irreversível - com danos muito severos, planta praticamente morta. Qualidade do fuste: bom - em perfeito estado, sem injúrias; regular - apresentou poucas injúrias; e ruim - apresentou injúrias severas.

Avaliação de conflitos com fiação aérea e com raízes. Com fiação aérea - plantas que afetam a fiação ou que poderão afetar (potencial). Com raízes (MARANHO \& PAULA, 2014): nenhum, quando as raízes não se encontram expostas; potencial, quando as raízes estão apontando na superfície do solo, que causarão danos futuros; e presente, quando as raízes estão causando algum problema, como levantamento de calçadas ou rachaduras.

A origem das plantas. Nativa (nativa do Brasil) ou exótica (introduzida de outros países) indicada de acordo com pesquisa bibliográfica.

Para os dados quantitativos, a partir do levantamento dos indivíduos, foram realizados cálculos de frequência relativa.

Além disso, realizaram-se outras observações, como a sombra fornecida pelas plantas e a fauna presente no local.

\subsubsection{ORGANIZAÇÃO DE MAPA}

Para a confecção do mapa da Praça Marechal Deodoro da Fonseca com a espacialização das plantas, optouse por utilizar seu agrupamento e classificação como: arbustos, árvores, palmeiras, pinheiros e cactos. Essa escolha foi devido a melhor forma de visualizar e compreender a composição florística desse ambiente, indicando os indivíduos quantitativamente.

Os dados cartográficos foram tratados no software QGIS, que é livre e aberto. Posteriormente, os dados levantados a campo nas campanhas de identificação das espécies foram inseridos no banco de dados a partir da criação de feições pontuais, às quais foram associadas às informações do nome popular, do nome científico e da classificação, permitindo a posterior geração do mapa de distribuição.

\section{RESULTADOS}

Foram catalogadas 368 plantas entre: árvores (237), arbustos (88), pinheiros (12), palmeiras (30) e cactos (1) (Tabela 1). Identificadas 28 famílias botânicas, sendo que as famílias Fabaceae e Bignoniaceae, apresentaram $18 \%$ e 15\%, respectivamente, do total de espécies identificadas. A família Fabaceae foi encontrada com maior número de espécies em levantamento realizado em um fragmento urbano na região metropolitana de Porto Alegre (TROIAN et al., 2011), arborização urbana do bairro Ferraropólis na cidade de Garça-SP (NUNES et al., 2013) e nas praças do bairro de Neópolis, Natal-RN (SILVA e ALMEIDA, 2016). Porém, para Batista et al. 
(2013), Myrtaceae foi a família botânica que predominou em diversidade de espécies, em levantamento realizado na praça Dom Assis, Jaboticabal - SP.

Tabela 1: Espécies, famílias botânicas e características das plantas encontradas na Praça Marechal Deodoro da Fonseca, Itaqui -

\begin{tabular}{|c|c|c|c|c|c|}
\hline \multicolumn{6}{|c|}{ RS. } \\
\hline FAMÍLIA & NOME CIENTÍFICO & PORTE & STATUS & $\mathbf{N}$ & FR (\%) \\
\hline \multirow[t]{3}{*}{ Apocynaceae } & Plumeria rubra & A & $E$ & 2 & 0,543 \\
\hline & Tabernaemontana catharinensis & A & $\mathrm{N}$ & 1 & 0,272 \\
\hline & Thevetia peruviana & A & $\mathrm{E}$ & 1 & 0,272 \\
\hline Aracaceae & *Palmeiras & PA & - & 30 & 8,152 \\
\hline Araceae & Monstera deliciosa & $A B$ & $\mathrm{E}$ & 2 & 0,543 \\
\hline Araliaceae & Schefflera arboricola & $A B$ & $E$ & 2 & 0,543 \\
\hline Araucariaceae & Araucaria angustifolia & $\mathrm{PI}$ & $\mathrm{N}$ & 1 & 0,272 \\
\hline Asparagaceae & Dracaena margina & $A B$ & $\mathrm{E}$ & 1 & 0,272 \\
\hline \multirow[t]{2}{*}{ Bignoniaceae } & Handroanthus heptaphyllus & $A$ & $\mathrm{~N}$ & 14 & 3,804 \\
\hline & Jacaranda mimosifolia & A & $E$ & 40 & 10,870 \\
\hline Cactaceae & Epiphyllum oxipetalum & $A B$ & $\mathrm{~N}$ & 1 & 0,272 \\
\hline Cupressaceae & *Pinheiro cipreste & $\mathrm{PI}$ & $E$ & 9 & 2,446 \\
\hline Cycadaceae & Cycas revoluta & $\mathrm{Cl}$ & $E$ & 2 & 0,543 \\
\hline Dilleniaceae & Dillenia indica & $A$ & $E$ & 5 & 1,359 \\
\hline Ericaceae & Rhododendron simsii & $A B$ & $E$ & 3 & 0,815 \\
\hline \multirow[t]{7}{*}{ Fabaceae } & Bauhinia variegata & $A$ & $\mathrm{~N}$ & 2 & 0,543 \\
\hline & Calliandra brevipes & $A B$ & $\mathrm{~N}$ & 4 & 1,087 \\
\hline & Cassia fistula & $A$ & $\mathrm{E}$ & 1 & 0,272 \\
\hline & Herythrina speciosa & A & $\mathrm{N}$ & 1 & 0,272 \\
\hline & Peltophorum dubium & A & $\mathrm{N}$ & 3 & 0,815 \\
\hline & Schizolobium parahyba & A & $\mathrm{N}$ & 1 & 0,272 \\
\hline & Tipuana tipu & $A$ & $E$ & 52 & 14,130 \\
\hline Juglandaceae & Juglans regia & $A$ & $E$ & 2 & 0,543 \\
\hline Lythraceae & Lagerstroemia indica & A & $\mathrm{E}$ & 33 & 8,967 \\
\hline \multirow[t]{2}{*}{ Malvaceae } & Hibiscus rosa-sinensis & $A B$ & $\mathrm{E}$ & 24 & 6,522 \\
\hline & Hibiscus spp. & $A B$ & $\mathrm{E}$ & 1 & 0,272 \\
\hline \multirow[t]{3}{*}{ Moraceae } & Ficus benjamina & $A$ & $E$ & 20 & 5,435 \\
\hline & Ficus benjamina "Variegata" & A & $\mathrm{E}$ & 1 & 0,272 \\
\hline & Morus nigra & A & $E$ & 3 & 0,815 \\
\hline \multirow[t]{6}{*}{ Myrtaceae } & Callistemon citrinus & A & $\mathrm{E}$ & 1 & 0,272 \\
\hline & Campomanesia guazumaefolia & $A$ & $\mathrm{~N}$ & 1 & 0,272 \\
\hline & Eugenia pyriformis & A & $\mathrm{N}$ & 1 & 0,272 \\
\hline & Eugenia uniflora & A & $\mathrm{N}$ & 4 & 1,087 \\
\hline & Melaleuca quinquenervia & $A$ & $\mathrm{E}$ & 1 & 0,272 \\
\hline & Syzygium cumini & A & $E$ & 2 & 0,543 \\
\hline
\end{tabular}




\begin{tabular}{l|l|c|c|c|c}
\hline Nyctaginaceae & Bougainvillea spectabilis & $\mathrm{AB}$ & $\mathrm{E}$ & 1 & 0,272 \\
\hline \multirow{2}{*}{ Oleaceae } & Ligustrum lucidum & $\mathrm{A}$ & $\mathrm{E}$ & 8 & 2,174 \\
\cline { 2 - 5 } & Olea europaea & $\mathrm{A}$ & $\mathrm{E}$ & 1 & 0,272 \\
\hline Pinaceae & *Pinheiro Pinus sp. & $\mathrm{PI}$ & $\mathrm{E}$ & 2 & 0,543 \\
\hline Proteaceae & Grevillea robusta & $\mathrm{A}$ & $\mathrm{E}$ & 30 & 8,152 \\
\hline Rosaceae & Rosa spp. & $\mathrm{AB}$ & $\mathrm{E}$ & 25 & 6,793 \\
\cline { 2 - 5 } & Spiraea x vanhouttei & $\mathrm{AB}$ & $\mathrm{E}$ & 1 & 0,272 \\
\hline Rutaceae & Citrus x limonia & $\mathrm{A}$ & $\mathrm{E}$ & 1 & 0,272 \\
\hline Sapindaceae & Cupania vernalis & $\mathrm{A}$ & $\mathrm{N}$ & 4 & 1,087 \\
\hline Solanaceae & Brunfelsia uniflora & $\mathrm{AB}$ & $\mathrm{E}$ & 21 & 5,707 \\
\hline Theaceae & Camellia japonica & $\mathrm{AB}$ & $\mathrm{E}$ & 1 & 0,272 \\
\hline Verbenaceae & Duranta repens “Aurea” & $\mathrm{AB}$ & $\mathrm{E}$ & 1 & 0,272 \\
\hline Total & \multicolumn{2}{|c|}{} & & 368
\end{tabular}

Porte: $\mathrm{A}$-árvore, $\mathrm{AB}$ - arbusto; Origem: $\mathrm{N}$ - nativa, $\mathrm{E}$ - exótica; $\mathrm{N}$ - número de plantas; $\mathrm{FR}$ - frequência relativa. * Pinheiros e Palmeiras não foram identificados em nível de espécie.

Das plantas encontradas na praça, $69 \%$ são de espécies exóticas, mostrando a hegemonia das plantas consideradas "diferentes" sobre as nativas. Os vegetais foram sendo plantados na praça de forma aleatória e de acordo com o conveniente para sua época, como por exemplo, a oliveira (Olea europaea) que é remanescente. Foi plantada juntamente com várias outras mudas, nas vias urbanas centrais da cidade, mas que não se adaptaram e não resistiram ao tempo, sobrando apenas o exemplar da praça (não publicado). A hegemonia das plantas exóticas sobre as nativas, cultivadas nos espaços verdes urbanos, é confirmada em levantamento realizado em várias cidades, dentre as quais, Lajeado - RS (RUSCHEL e LEITE, 2002), Valente BA (BARRETO et al., 2014), Bairro Neópolis em Natal - RN (SILVA e ALMEIDA, 2016) e Areia-PB (FABRICANTE et al., 2017). Segundo Carvalho et al. (2007) o conhecimento da flora brasileira, seus atributos econômicos, sua fisiologia, importância ecológica, podem vir a popularizar o uso das espécies nativas na arborização, contribuindo para a preservação das mesmas e com a formação de um caráter de identidade nacional, regional e até local, que se expressaria no contexto paisagístico das cidades e/ou de espaços urbanos.

Dentre as plantas exóticas, destaca-se a árvore do dinheiro ou flor de abril (Dillenia indica), planta ornamental que apresenta frutos curiosos e que podem ser utilizados no preparo de doces. Além dessa, foram encontradas outras plantas que produzem frutos ou sementes comestíveis, tais como: pitangueira (Eugenia uniflora), amoreira (Morus nigra), pinheiro (Araucaria angustifolia), uvaia (Eugenia pyriformis), oliveira (Olea europaea), limoeiro (Citrus x limonia) e sete capotes (Campomanesia guazumaefolia), totalizando 8 espécies. De Agelis e De Angelis Neto (2000), encontraram 10 espécies de árvores frutíferas no levantamento realizado em praças, na cidade de Maringá - PR. Para Batista et al. (2013), foram 6 espécies frutíferas catalogadas para a praça Dom Assis, Jaboticabal - SP, dentre elas, a pitangueira e a uvaia encontradas em Itaqui - RS.

As espécies de maior frequência relativa (Tabela 1) encontradas na praça foram: Tipuana tipu, Jacaranda mimosifolia, Grevillea robusta, Lagerstroemia indica e Palmeiras. Tipuanas foram plantadas ao longo das margens que acompanham as Ruas Dr. João Dubal Gourlart e Euclides Aranha (Figura 3). De Agelis e De Angelis Neto (2000), também encontraram a espécie Tipuana tipu entre as de maior frequência em praças da cidade de Maringá-PR. Porém, em praças do bairro Neópolis, Natal - RN, Silva e Almeida (2016), encontraram as espécies Cocus nucifera e Mangifera indica L. 


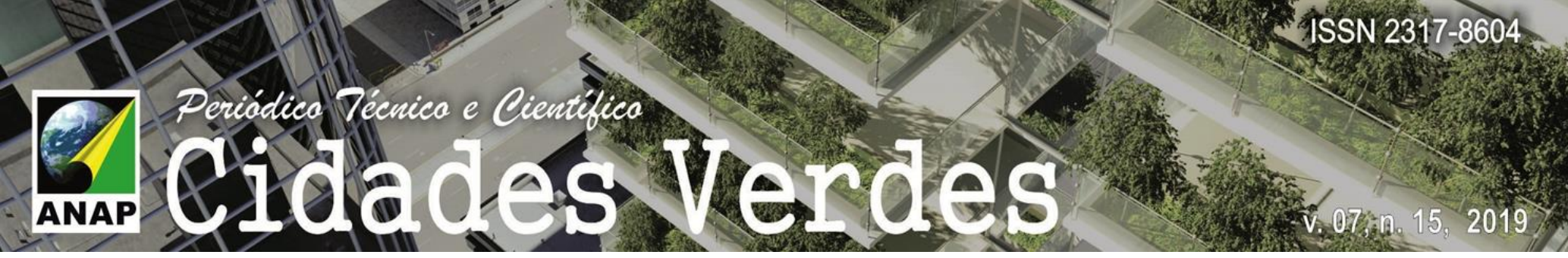

Figura 3. Mapa da composição florística e sua espacialização na Praça Marechal Deodoro da Fonseca. Itaqui-RS, 2017.

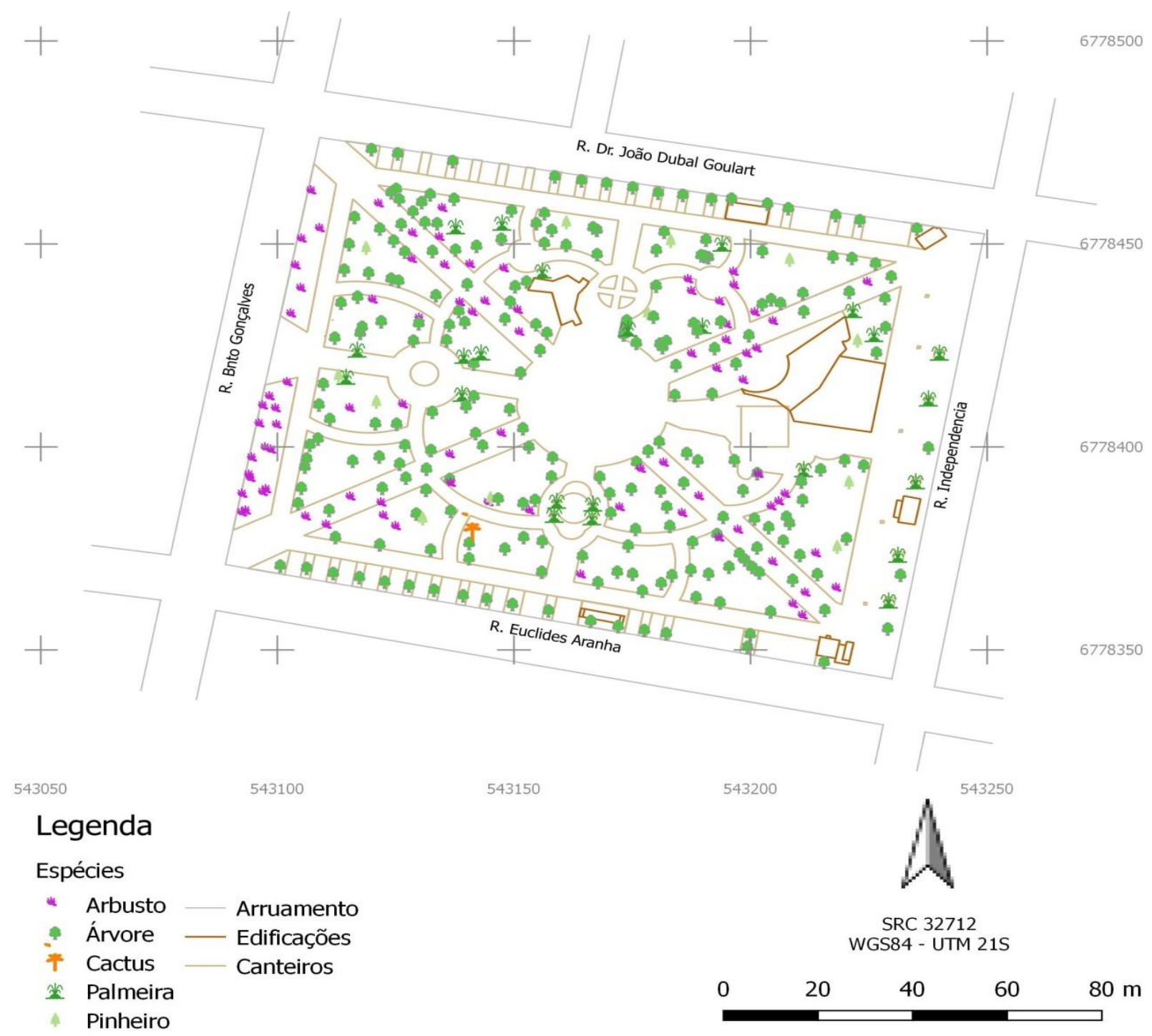

As árvores encontradas com maior frequência equivalem a 12\% do número total de espécies identificadas. Esse monopólio pode vir a ser prejudicial do ponto de vista técnico, pois segundo De Agelis e De Angelis Neto (2000), essa é uma situação de risco a que parte considerável dessa arborização fica exposta face a um eventual ataque de pragas ou incidência de patógenos.

A fauna local é composta por diversidade de insetos, aracnídeos e pássaros. Chama a atenção de todos, a engenharia na construção dos ninhos do pássaro chamado popularmente de tecelão (Figura 4), que todos os anos constroem vários ninhos nas árvores (Tipuana tipu) mais externas da praça, ao longo da Rua Independência (Figura 4). Além disso, essa praça era visitada por uma temporalmente por uma macaca (bugio). 


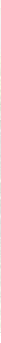

Figura 4: Árvore centenária com diversidade de plantas epífitas (A) e fauna (B) encontrada na Praça Marechal Deodoro da Fonseca. Itaqui-RS, 2017.
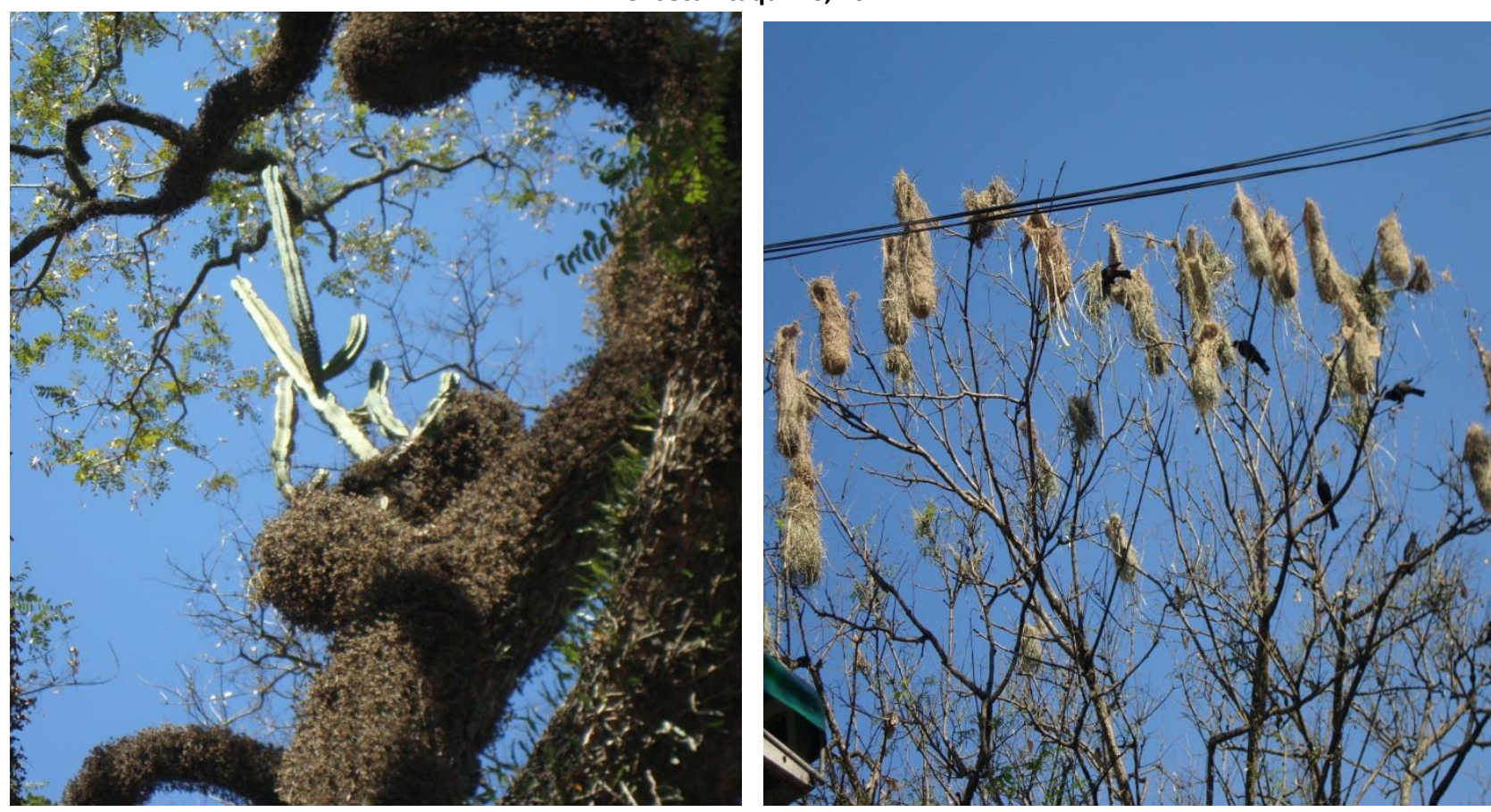

(Foto: acervo pessoal, 2016)

A praça apresenta vários bustos e monumentos de personagens históricos e na região central fica saliente um monumento que é utilizado até os dias de hoje para guarnecer a "chama crioula", nas festividades tradicionalistas gaúchas, no mês de setembro (Figuras 5 e 6). Além disso, encontram-se vários bancos espalhados que são utilizados pela população no geral, em momentos de lazer (Figuras 5 e 6). Corroborando o que foi citado por Ayres et al. (2015), que as praças eram um espaço cívico destinado à realização de discursos e espetáculos, à contemplação, ao encontro de pessoas e ao lazer, e nelas se colocavam estátuas e monumentos. Porém, nos dias atuais, vários pesquisadores as denominam como área verde urbana, tendo em vista as funções ambientais e sociais que desempenham. 


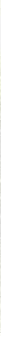

Figura 5: Aspecto geral da organização central da Praça Marechal Deodoro da Fonseca. Itaqui-RS, 2017.

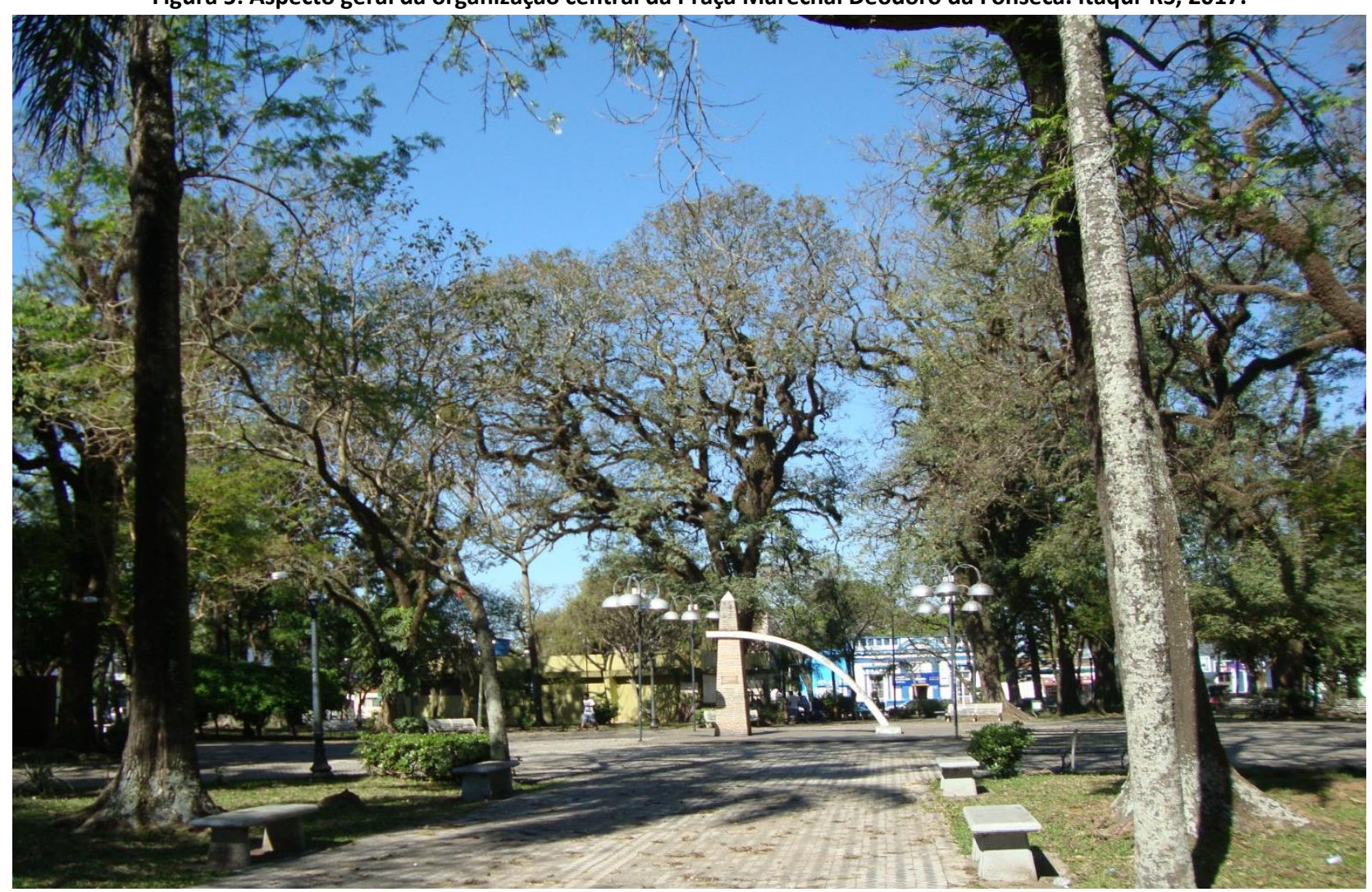

(Foto: acervo pessoal, 2016)

Figura 6: Vista lateral da Praça Marechal Deodoro da Fonseca. Itaqui-RS, 2017.

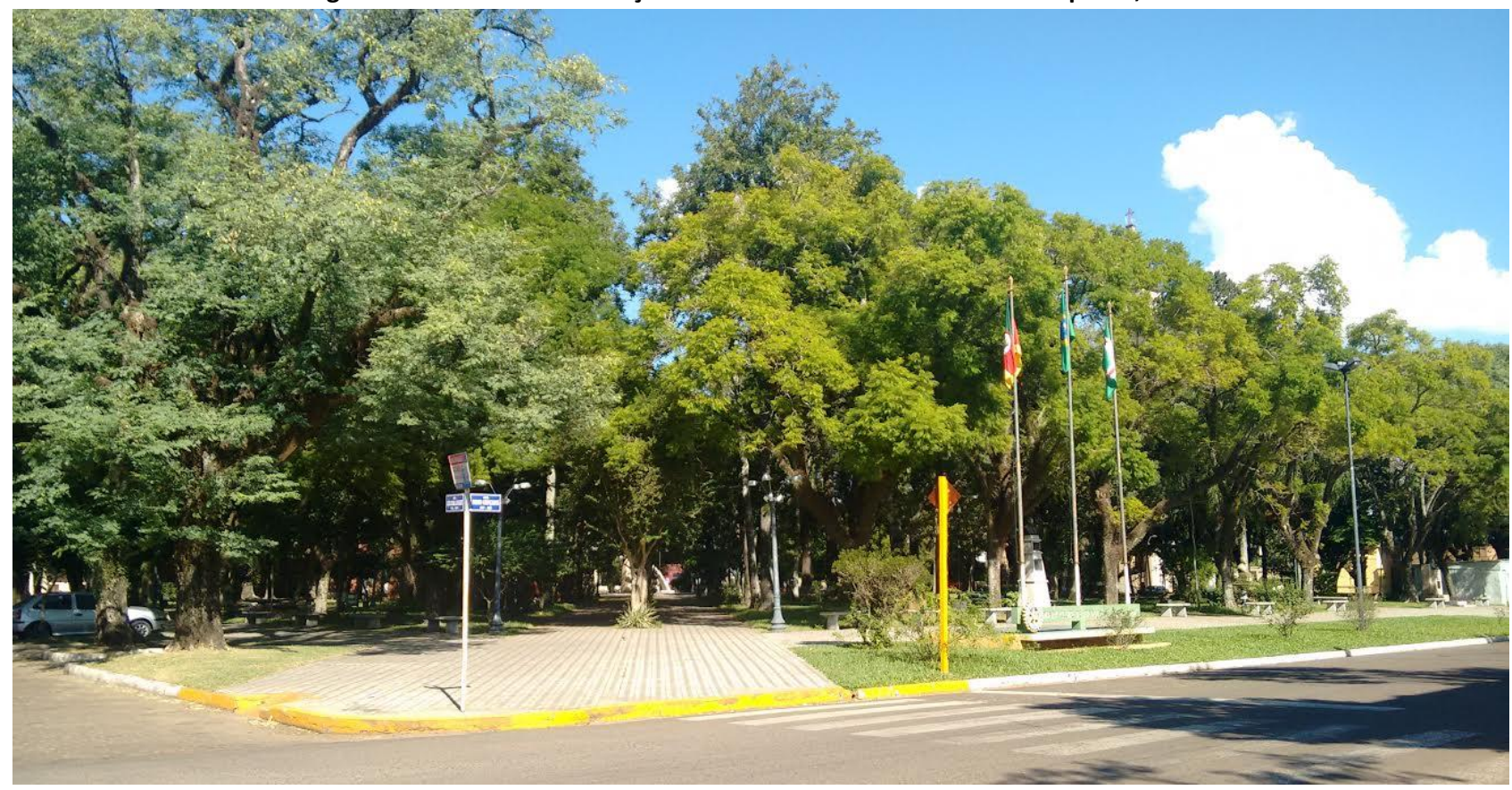

(Foto: acervo pessoal, 2017) 


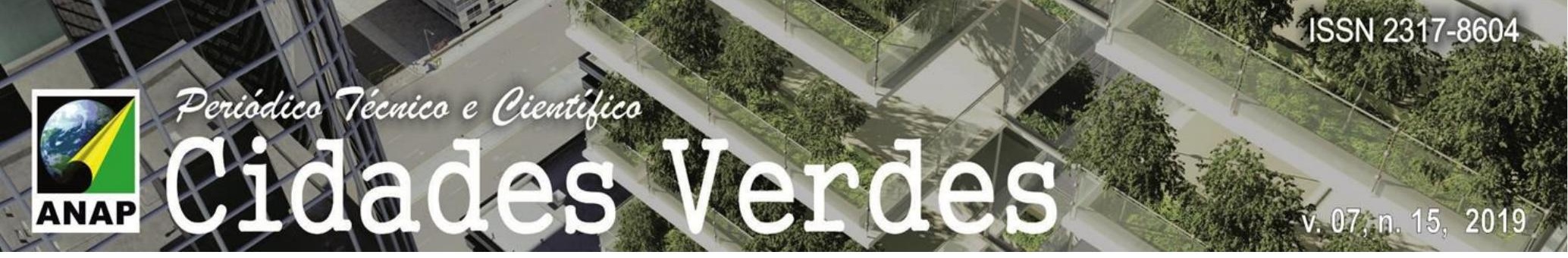

Árvores centenárias, imponentes e belas, como as tipuanas e os jacarandás, compõem esse ambiente, no entanto, esses indivíduos que fazem parte da composição florística desse local estão envelhecendo, como mostram os dados das figuras 5 e 6 . Encontram-se $46 \%$ das árvores com copas que apresentam a classificação entre danificada e dano irreversível, e para fuste $54 \%$ ficaram classificadas entre regular e ruim (Figura 7). Por isso da importância de se realizar o levantamento da composição florística das áreas verdes urbanas, que segundo Caldeira et al. (2011) é um estudo realizado a fim de se avaliar as diversidades para recomposição de espécies existentes em uma área. Nesse caso, o poder público já deveria ter realizado uma análise e estabelecido um planejamento estratégico para realizar um acompanhamento e substituição da flora, de acordo com a necessidade. Concordando com Ayres et al. (2015), quando salientam que o poder público precisa desenvolver estratégias voltadas para a manutenção e conservação de área verde no centro das cidades.

Figura 7: Qualidade da copa (A) e do fuste (B) das árvores da Praça Marechal Deodoro da Fonseca. Itaqui-RS, 2017.

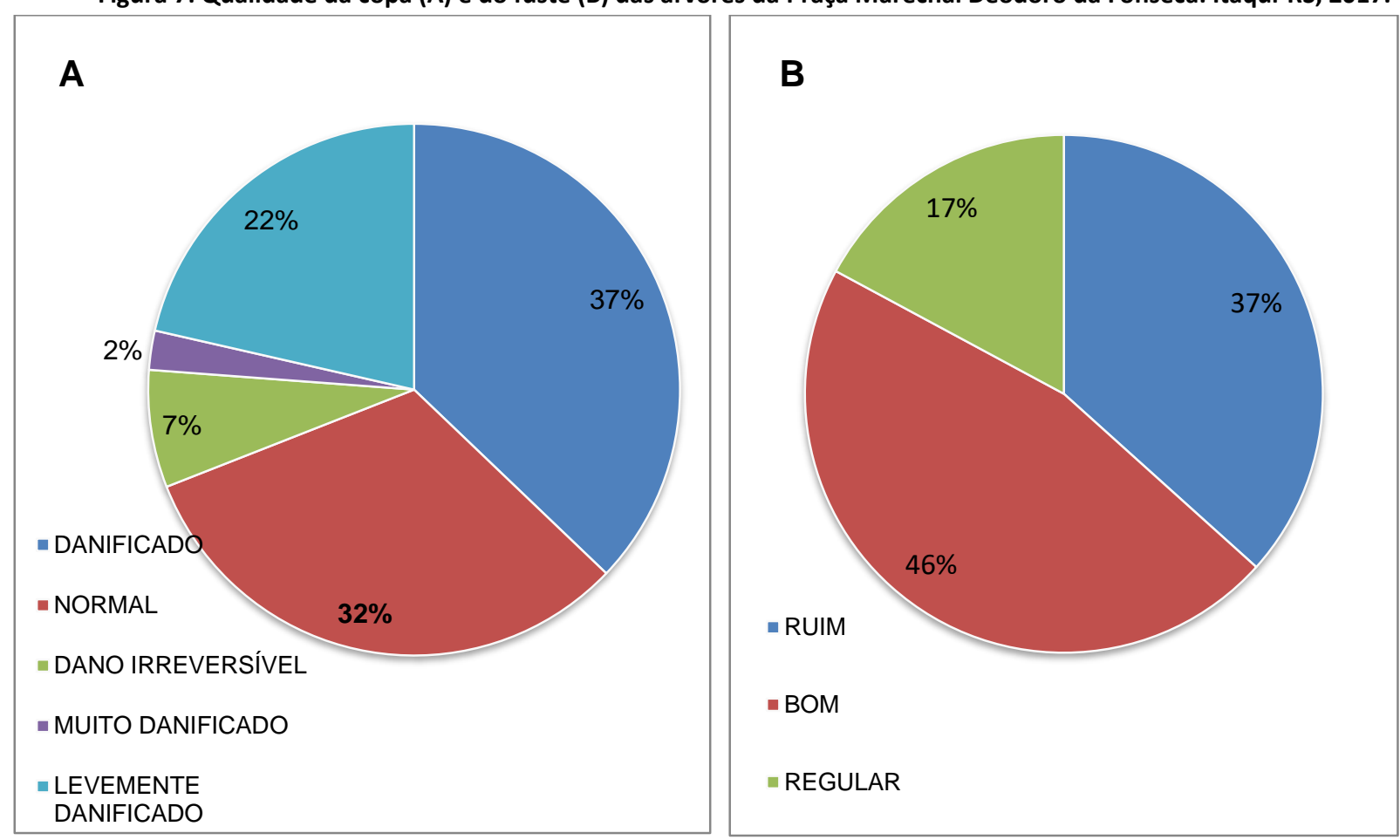

Para conflitos com fiação, encontrou-se apenas 3\% das plantas relacionadas a essa problemática, portanto, praticamente inexistente.

Com relação ao conflito de raízes, $25 \%$ apresentam algum conflito e $12,5 \%$ das plantas apresentam potencial em desenvolver algum conflito. Para Barreto et al. (2014), 16,89\% das plantas apresentaram conflitos que danificaram totalmente o calçamento da arborização dos logradouros. Das sete espécies indicadas por Nunes et al. (2013) como espécies que apresentaram maiores danos as calçadas em bairro na cidade de Garça-SP, duas delas foram encontradas na praça, em Itaqui, Ficus benjamina e Jacaranda mimosifolia.

Observou-se na praça em Itaqui, que a relação vegetação x pavimentação, não é harmônica, pois observamse sinais de reparos em diversos locais. Sendo que as raízes de algumas árvores precisaram ser retiradas e o passeio reparado em vários pontos, inclusive nos logradouros adjacentes. Diferente do que foi observado por Ayres et al. (2015), nas praças de Mamborê - PR, que não apresentaram áreas de pavimentação danificadas por raízes de árvores. 


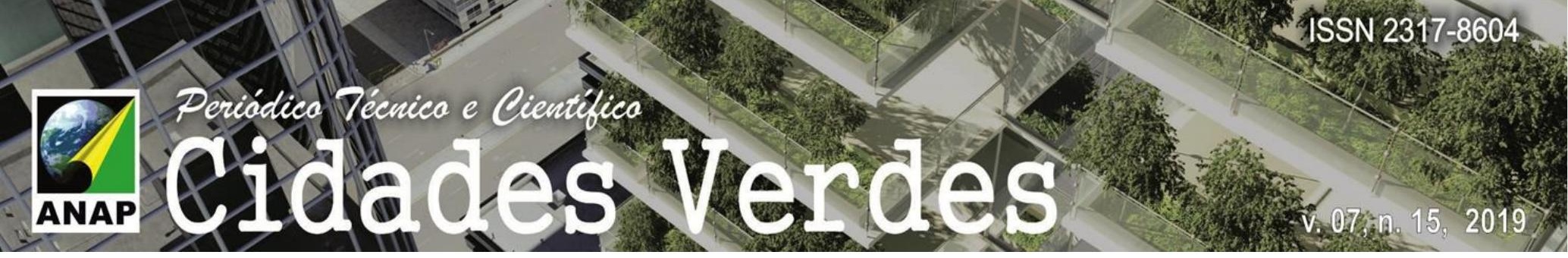

\section{CONSIDERAÇÕES FINAIS}

A composição florística da Praça Marechal Deodoro da Fonseca, de Itaqui - RS, cumpre com sua função ambiental quanto à área verde urbana, além de ser um local adequado utilizado pela população para o lazer e convivência. Entretanto, observou-se falta de planejamento com relação à escolha das plantas e o espaço utilizado para o plantio.

A praça apresenta 368 plantas, sendo 237 árvores, 88 arbustos, 12 pinheiros, 30 palmeiras e 1 cactos. Foram identificadas 28 famílias botânicas, sendo que a Fabaceae foi a mais expressiva e as plantas exóticas se sobressaíram às nativas.

Parte das árvores encontradas na praça, principalmente no seu entorno são velhas, com avarias na copa e ou no fuste, e nesse sentido, existe a necessidade de ser realizado um estudo para a renovação e manutenção desse espaço.

\section{REFERÊNCIAS BIBLIOGRÁFICAS}

AYRES, A.C.B.F.; GALDINO, S. de J.; BOVO, M.C. As praças de Mamborê - PR enquanto áreas verdes urbanas. Cidades Verdes, v.3, n.4, p. 118-133, 2015.

BACKES, A.; NARDINO, M. Árvores, arbustos e algumas lianas nativas no Rio Grande do Sul. 2. ed. São Leopoldo: UNISINOS, 2003. $213 p$.

BACKES, A.; NARDINO, M. Nomes populares e científicos de plantas do Rio Grande do Sul. 2. ed. São Leopoldo: UNISINOS, 2004.

BARRETO, A.M.R.; PAULA A. de; BARRETO, P.A.B; BARRETO, M. das G.M.R. Diagnóstico da arborização urbana do Bairro Dionísio Mota, município de Valente, Estado da Bahia. Enciclopédia Biosfera, v.10, n.19; p. 2108-2119, 2014.

BATISTA, G.S.; BORELLA, H.D.; GIMENES, R.; ROMANI, G. de N.; PIVETTA, K.F.L. Análise quali-quantitativa da vegetação e dos elementos arquitetônicos da praça Dom Assis, Jaboticabal, São Paulo. Revista Brasileira de Horticultura Ornamental, v. 19, no.1, p. 7-18, 2013.

BRITO, C.R.; CASTRO, J.P.M.de; BARROS, K.O.; FARIA, A.L.P. O uso de sig no inventário de árvores no Campus do Instituto Politécnico de Bragança, Portugal. Geografia Ensino \& Pesquisa, v. 16, n. 3, p. 157-177, 2012.

CARVALHO, G.M.; ROQUE, N.; GUEDES, M.L.S. Levantamento das espécies arbóreas da Universidade Federal da Bahia, Salvador, Bahia. Sitientibus Série Ciências Biológicas, v. 7, n. 4, p. 377-387, 2007.

DE ANGELIS, B.L.D.; DE ANGELIS NETO, G. A vegetação e as praças na cidade de Maringá/PR. Acta Scientiarum, v. 22, n. 5, p. 1455-1461, 2000.

DOURADO, L.A.C.; SILVA, E.A. Espacialização e ordenamento das praças, espaços de recreação e lazer, na estância turística Ilha Solteira - SP. Revista Eletrônica da Associação dos Geógrafos Brasileiros - Seção Três Lagoas, v. 2, n. 2, p. 67-86, 2005

FABRICANTE, J.R.; SANTOS, J.P.B.; ARAÚJO, K.C.T.; COTARELLI, V.M. Utilização de espécies exóticas na arborização e a facilitação para o estabelecimento de casos de invasão biológica. Biotemas, v.30, n.1, p. 55-63, 2017.

GARCIA, E.B.; PARFITT, C.M. Indicadores de áreas verdes públicas urbanas: O caso de Pinheiro Machado RS. In: 1을 Congresso Internacional de Espaços Públicos. Porto Alegre, RS, 2015. Anais... Núcleo de Estudos da Cidade da Faculdade de Arquitetura e Urbanismo PUCRS. Porto Alegre, 19 a 22 de outubro de 2015. 


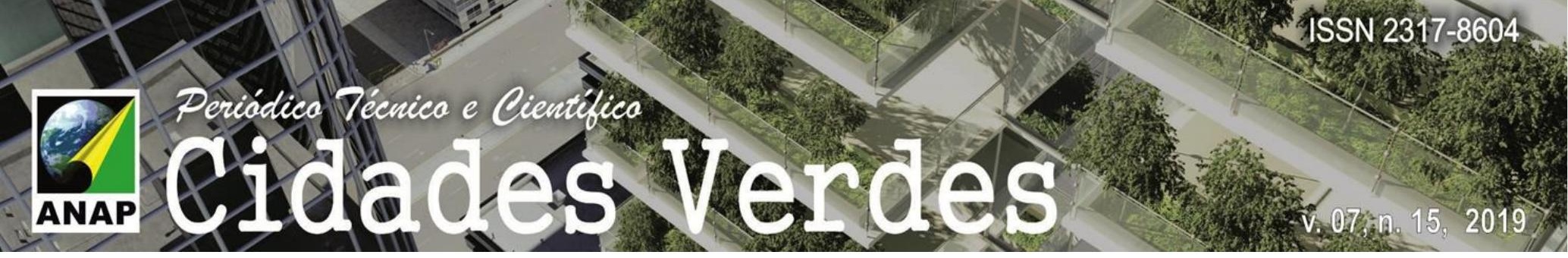

IBGE. Portal Cidades@. Rio de Janeiro: IBGE, 2017. Disponível em <http://cidades.ibge.gov.br> Acesso em 19 de julho de 2017.

LORENZI, H. Árvores Brasileiras: manual de identificação e cultivo de plantas arbóreas do Brasil. 4. ed. Nova Odessa: Plantarum, 2002a. v 1.

LORENZI, H. Árvores Brasileiras: manual de identificação e cultivo de plantas arbóreas do Brasil. 2. ed. Nova Odessa: Plantarum, 2002b.v 2.

LORENZI, H.; SOUZA, H.M.; TORRES, M.A.V; BACHER, L.B. Árvores exóticas no Brasil: madeireiras, ornamentais e aromáticas. Nova Odessa: Plantarum, 2003.

LUSA, M.G.; BONA, C. Análise morfoanatômica comparativa da folha de Bauhinia forficata Link e B. variegata Linn. (Leguminosae, Caesalpinioideae). Acta Botanica Brasilica, v. 23, n.1, p.196-211, 2009.

MARANHO, A.S.; PAULA S.R.P. Diversidade em uma área verde urbana: avaliação qualitativa da arborização do campus da Universidade Federal do Acre, Brasil. Revista Agro@mbiente, v. 8, n. 3, p. 404-415, 2014.

NUNES, R.L.; MARMONTEL, C.V.F.; RODRIGUES, J.P.; MELO, A.G.C. Levantamento qualiquantitativo da arborização urbana do bairro Ferraropólis na cidade de Garça-SP. REVSBAU, v.8, n.1, p.65-74, 2013.

QGIS. QGIS 2.14.3 Essen. 2015. Disponível em www.qgis.org.

OLIVEIRA, K.A. de; JESUS, I.S. de. Espacialização e quantificação das áreas verdes no perímetro urbano do município de Rio Branco Acre. Anais... XV Simpósio Brasileiro de Sensoriamento Remoto - SBSR, XV. Curitiba - PR, 30 de abril a 05 de maio de 2011 , p.0877.

RUSCHEL, D.; LEITE, S.L.C. Arborização urbana em uma área da cidade de Lajeado, Rio Grande do Sul, Brasil. Caderno de Pesquisa Série Biologia, v. 14, n. 1, p. 07-24, 2002.

SOUZA, V.C. \& LORENZI, H. Botânica Sistemática: guia ilustrado para identificação das famílias de Fanerógamas e exóticas do Brasil, baseado em APG III. 3. ed. Nova Odessa: Plantarum, 2012.

SILVA, C.D.D.da; ALMEIDA, L.M.de. Composição florística e fitossociológica das praças do Bairro de Neópolis, Natal-RN. Carpe Diem: Revista Cultural e Científica do UNIFACEX, v. 14, n. 2, p. 86-103, 2016.

TEIXEIRA, I. F. SANTOS, N. R. Caracterização das áreas verdes do perímetro urbano de Santa Catarina- RS. Anais- Encontro Nacional de Estudos sobre o Meio Ambiente, e, 1991, Londrina. Anais... Londrina, 1991.

TROIAN, L.C.; KÄFFER, M.I.; MÜLLER, S.C.; TROIAN, V.R.; GUERRA, J.; BORGES, M.G.; GUERRA, T.; RODRIGUES, G.G.; FORNECK, E.D. Florística e padrões estruturais de um fragmento florestal urbano, região metropolitana de Porto Alegre, RS, Brasil. IHERINGIA Série Botânica, v. 66, n. 1, p. 5-16, 2011. 